Representaciones sociales sobre las y los adolescentes: voces del estudiantado aprendiz de maestro o maestra en el marco de su práctica docente en la escuela secundaria

\author{
Gutiérrez Álvarez, Edith \\ Representaciones sociales sobre las y los adolescentes: voces del estudiantado aprendiz de maestro o maestra \\ en el marco de su práctica docente en la escuela secundaria \\ Revista Educación, vol. 45, núm. 1, 2021 \\ Universidad de Costa Rica, Costa Rica \\ Disponible en: http://www.redalyc.org/articulo.oa?id=44064134024 \\ DOI: https://doi.org/10.15517/revedu.v45i1.41831
}

Esta obra está bajo una Licencia Creative Commons Atribución-NoComercial-SinDerivar 3.0 Internacional. 


\title{
Representaciones sociales sobre las y los adolescentes: voces del estudiantado aprendiz de maestro o maestra en el marco de su práctica docente en la escuela secundaria
}

\author{
Social Representation of Male and Female Adolescents: Voices of Apprentice Teachers Regarding Teaching \\ practices in secondary school
}

Edith Gutiérrez Álvarez

Escuela Normal Superior de México, México, México

edithdidi2003@yahoo.com.mx

iD http://orcid.org/0000-0002-6663-6365

\author{
DOI: https://doi.org/10.15517/revedu.v45i1.41831 \\ Redalyc: http://www.redalyc.org/articulo.oa?id=44064134024
}

Recepción: 22 Mayo 2020

Aprobación: 29 Septiembre 2020

\section{Resumen:}

Este artículo tiene como propósito analizar, comparar e interpretar las representaciones sociales que, sobre las y los adolescentes, manifiestan 15 aprendices de maestro ubicados en la Ciudad de México. Para visibilizar esas voces se procede a instaurar las representaciones sociales a través de la perspectiva procesual de Jodelet (1986). Para acceder a los testimonios, se da cauce a la elaboración de una entrevista a profundidad sobre la cual las y los aprendices de maestro hacen alusión a los conflictos, las actitudes y las interacciones que desarrollan durante sus prácticas con el estudiantado adolescente. En relación con los resultados, se puede constatar que las representaciones sociales tienen como punto de referencia el grado que cursa cada grupo de adolescentes. Por ejemplo, las y los aprendices de maestro representan al alumnado del primer grado con conductas infantiles y a veces apegadas a las directrices que señalan los y los docentes. Al respecto de las y los alumnos de segundo grado sándwich, se les asocia con la adopción de actitudes de rebeldía ante todo aquello que invoque el tono de autoridad. Por último, la representación social sobre las y los adolescentes que cursan el tercer grado se vincula con la seriedad con la que asumen sus tareas escolares, todo, en aras de obtener su certificado de estudio para continuar sin problemas el nivel bachillerato. En conclusión, los resultados dieron cuenta que las representaciones sociales que construyen los aprendices de maestro son diversas, pero al mismo tiempo, asociadas al grado de estudios que cursan las y los adolescentes de la escuela secundaria.

Palabras Clave: Representaciones sociales, Adolescentes, Escuela secundaria, Aprendices, Práctica docente.

\section{Abstract:}

Social representations of teenage boys and girls were analyzed, compared and interpreted by fifteen apprentice teachers in Mexico City. Jodelet's procedural perspective (1986) was used to visibilize their voices based on in-depth interviews with male and female apprentice teachers who discussed conflicts, attitudes and interactions observed during their practice sessions with the teenage student body. Social representations were found to be comparable to the grade of the teenager. For example, seventh graders (first year high school students) were described as displaying a childish behavior with a tendency with attachment to teacher guidelines. Eight graders (second year high school students) who are in a "sandwiched" grade, are more associated with being rebellious to any sort of authority figure. Lastly, ninth graders (third year high school students) are linked to exhibiting a more serious approach to schoolwork and aspiring to advance to upper secondary education. It is concluded that social representations by apprentice teachers regarding teenagers are varied but intrinsically associated with the grade of the student.

KeYWorDs: Social Representation, Teenagers, Adolescents, High School, Apprentice Teacher, Teaching Practice.

\section{INTRODUCCIÓN}

Para Moscovici (1979) una representación social consiste en algo que sustituye a otra cosa, sean personas u objetos. Las refiere como un corpus organizado de conocimientos a través de los cuales las personas hacen inteligible su visión individual y social. Asimismo, las concibe como el conjunto de ideas, concepciones e interacciones que, al ser compartidas por los miembros de un determinado grupo social, instalan una visión particular de entendimiento y funcionalidad. En sus palabras, "una representación social designa una forma 
de conocimiento científico, el saber de sentido común, cuyos contenidos manifiestan la operación de procesos generativos y funcionales socialmente caracterizados" (p. 474).

Jodelet (2011), una de las principales seguidoras de Moscovici, valora que la lente de las representaciones sociales ha sido abordada en distintos campos de investigación, como la educación y la salud. Lo resume así: "la perspectiva de la representación social ha encontrado un eco muy favorable en los dominios de investigación caracterizados por la complejidad de los fenómenos o sistemas" (p.135).

Urbina y Ovalles (2018) coinciden en que las representaciones sociales apuntan a la transversalidad, al permitir la integración de algunas disciplinas como: "la antropología, sociología, psicología cognitiva” (p.496). Araya (2002) aprecia que la teoría de las representaciones sociales ha llegado a tal punto que los investigadores de algunos países de América Latina, como México, Brasil y Venezuela, las han incorporado. Tales distinciones funcionan como punto de partida para el desarrollo de este trabajo, pues a decir de Araya (2002), "Emprender estudios acerca de la representación de un objeto social [...] permite reconocer los modos y procesos de constitución del pensamiento social, por medio del cual las personas construyen y son construidas por la realidad social" (p.12).

Un criterio fundamental para abordar el presente estudio requiere centrarse en el llamado de la problematización, a la cual Sánchez (1993) reconoce como un proceso enclavado en decisiones que los investigadores refieren para su estudio.

En términos concretos, para interpretar las representaciones sociales creadas por las y los maestros en formación es necesario situarlos en su contexto, y, más aún, ligados con algunos recortes del entramado de su realidad.

$\mathrm{Al}$ respecto, es conveniente aclarar que la formación inicial de las y los aprendices de maestro se desarrolla en la Escuela Normal Superior de México (ENSM), institución formadora de docentes para atender el nivel educativo de la escuela secundaria. Lo anterior está en correspondencia con las pautas curriculares establecidas en el Plan de Estudios 1999 (Secretaría de Educación Pública [SEP], 2010). En él se instaura una dinámica de inserción a las aulas de las escuelas secundarias desde los semestres tercero y sexto; no obstante, durante los semestres séptimo y octavo, las y los estudiantes normalistas desarrollan sus prácticas en condiciones reales de trabajo.

En este sentido, la aproximación casi permanente a través de la práctica docente en la escuela secundaria permite advertir que las y los mencionados estudiantes normalistas son aprendices de maestro, y no es raro entonces que configuren una plataforma de significaciones que son el resultado de los vínculos establecidos con el alumnado. Al respecto, existen estudios (citado por Gutiérrez 2011, 2013), que colocan al alumnado normalista en un ambiente escolar de incertidumbre cada vez que las y los adolescentes de la escuela secundaria alteran el equilibrio durante la impartición de sus clases (citado por Gutiérrez, 2011, 2018).

Ahora bien, en lo que atañe directamente al escenario donde se insertan las y los aprendices de maestro, se muestran estudios de Gutiérrez (2018), Lozano (2010) y Levinson (2012) que resultan afines al vislumbrar que la escuela secundaria discurre entre problemas no resueltos; pero, además, en la experiencia del presente trabajo, las y los normalistas expresan tensiones e incertidumbres al momento de interactuar con las y los adolescentes; incluso, algunas veces han vivido momentos de indecisión al respecto de continuar su carrera de docente (Gutiérrez, 2011).

Como puede notarse, es recurrente un escenario escolar con disposiciones poco favorables durante la interacción con las y los aprendices de maestro. Esa realidad convoca a concentrar la atención en algunas parcelas de su mundo social. Por consiguiente, indagar esas particularidades requiere la siguiente pregunta de investigación: ¿cuáles son las representaciones sociales que expresan las y los aprendices de maestro con respecto al estudiantado adolescente de la escuela secundaria?

Se ha dicho que el propósito de este trabajo es analizar, comparar e interpretar las representaciones sociales que sobre las y los adolescentes manifiestan 15 aprendices de maestro ubicados en la ENSM. 
A ese respecto, se ha procedido a organizar el trabajo en cuatro apartados: el primero destaca algunas concepciones sobre adolescencia y práctica docente, ambas consideradas claves para sostener este estudio, a la vez se integra el referente teórico de las representaciones sociales. En segundo lugar, se presenta el proceder metodológico mediante el cual no sólo se sustenta la perspectiva procesual de las representaciones sociales, sino también se procede a la elección de las y los informantes, y del instrumento de acopio de información (entrevista a profundidad) con sus respectivos ejes temáticos. En el tercer apartado se comparte, el análisis y discusión de resultados a través del cual se visibiliza el universo de representaciones sociales, que manifiestan los aprendices de maestros sobre las y los adolescentes de la escuela secundaria. Por último, se detallan las conclusiones y referencias.

\section{Marco teórico}

La dinámica de cualquier trabajo de investigación requiere referentes teóricos diversificados que permitan elucidar un panorama más holístico sobre la temática de estudio. En este caso, el primero concierne a las y los adolescentes, que llevan el papel principal del presente trabajo, en seguida surgen algunas perspectivas sobre la práctica docente y, por último, se describe la teoría sobre las representaciones sociales.

\subsection{Adolescencia}

Respecto a las definiciones sobre la adolescencia, cabe destacar su carácter polisémico. Algunos autores la consideran un periodo que trae consigo transformaciones físicas, cognitivas, sociales y fisiológicas. Papalia y Wendkos (2001), incluso, mencionan que es un período de desarrollo social y moral. Sin embargo, es habitual que al hablar sobre adolescencia cada sociedad requiera instaurar sus propias pautas. Algunas líneas básicas de entendimiento sostienen que alguien adolece y, al amparo de esa aproximación, establecen principios que caracterizan a esa etapa de la vida con padecimientos y tensiones, que necesariamente debe palearse a través de la plataforma de inculcaciones impuestas por los adultos.

Por otra parte, más allá de la visión adultocéntrica, se advierten posicionamientos en los que las y los adolescentes son concebidos como agentes sociales que contravienen lo establecido, sobre todo al entrar en relación dialéctica con los planteamientos esencialmente mecanicistas. (Fize, 2004; Erickson, 2004).

Las concepciones de Fize (2004) y Krauskopf (2000) configuran a las y los jóvenes como participantes activos en su escenario social, por lo tanto y en concordancia con lo aludido, sus actuaciones no están supeditadas a las lógicas homogéneas inscritas en los intereses adultocéntricos. De ahí que sería ingenuo formular certezas absolutas que estén en sintonía con la ideación de esos esquemas tradicionales. Dicho de otra manera, este proceso de desmitificación sobre la adolescencia es una de las características más notables para enunciar que las y los adolescentes se movilizan en una dinámica progresiva donde su preocupación clave, pone de manifiesto su interés por conseguir un sitio en el mundo (Fize, 2004). En este punto se considera oportuno establecer, la distinción entre una concepción restringida socialmente sobre la adolescencia y un pensamiento que insiste en superar los cánones conservadores, ya que ambas elaboraciones teóricas sobre adolescencia ofrecen un sinnúmero de interpretaciones. Consecuentemente, en este estudio se presta una imperiosa atención a todo aquello que apunte a una visión sobre adolescencia que no atienda al orden instituido, tal como lo expresa (Fize, 2004).

\subsection{Práctica docente}

La práctica docente ocupa una posición comúnmente ligada a los aspectos fundamentales de la enseñanza en las aulas. Sin embargo, son notorias las marcas particulares que cada perspectiva teórica le imprime. Algunos 
autores se circunscriben en definiciones caracterizadas por su alta homogeneidad, al respecto, De Lella (1999) configura la práctica docente como el proceso enseñanza-aprendizaje que el profesorado establece en el espacio áulico. Martínez (2012), la concibe como la realización de las actividades que incumben al profesorado durante su permanencia en las aulas; el trasfondo es la concreción de los propósitos. No obstante, Hernández (2011) analiza la práctica docente involucrando el ámbito macro estructural, el cual -expresa la autora- involucra un clima de incertidumbres y es desencadenante de las afectaciones en el quehacer docente. En esa misma dirección, Gutiérrez (2018) agrega que la práctica docente representa una forma de pensamiento social distinto al guardar una estrecha relación con las condiciones contextuales en las que se moviliza el profesorado. Carr (2002) manifiesta que la práctica docente no sólo es la síntesis de los designios económicos, políticos, sociales, materiales e históricos, sino también refleja intenciones, sentido y significaciones que las y los profesores construyen con respecto al desarrollo de su trabajo.

En ese sentido, la práctica docente focaliza sus acciones en los significados que el profesorado comparte en su interrelación con las y los otros. Para Feixa (2010), toda concepción se enmarca en el significado que las y los maestros atribuyen de manera significativa a un determinado fenómeno.

Otra apreciación sobre la práctica docente es que ésta no es un problema vinculado con la teoría, sino una actividad práctica en la que el propósito es enseñar de manera deseable (Carr, 1998). En palabras de Contreras (1990): "es la práctica la que determina el valor de cualquier teoría educativa, en vez de ser la teoría la que determine el valor de cualquier práctica educativa” (p.140).

\subsection{Las representaciones sociales}

Moscovici (1979), autor de origen rumano pionero de las representaciones sociales, realizó estudios de doctorado en la Sorbona de París e hizo su tesis bajo la dirección del psicoanalista Daniel Lagache. Sus preguntas de investigación analizan cómo el psicoanálisis se le representa y modela al gran público, y a través de qué caminos se construye la imagen que se tiene de él. Dicho estudio accede a la subjetividad de las clases medias, población obrera, población estudiantil, población liberal y otros. Las preguntas de acopio de información que realizó sobre el psicoanálisis destacan tres dimensiones: información, campo de representación y actitud. Ahora bien, la dimensión de la información, se concreta en recuperar el bagaje de conocimientos sobre el citado psicoanálisis. La cuestión referida al campo de representación concreta o materializa la representación. Por último, la actitud se supedita a la aprehensión de las emociones que cada grupo social manifiesta, sean aprobatorias o desaprobatorias sobre la temática vertida. De esa manera, una representación social integra lo que se sabe, lo que se interpreta y la forma en que se actúa (Araya, 2002).

En los resultados obtenidos en la investigación de Moscovici (1979) cada grupo social al amparo de su contexto de pertenencia tiene una cierta concepción sobre el psicoanálisis. De esa manera el lenguaje científico del mismo, cobra un orden distinto según los alcances cognitivos de los miembros de un determinado grupo social.

El estudio de Moscovici (1979) denota, pues, que cada grupo concede al psicoanálisis un sentido muy particular de acuerdo a su contexto, lo que tiene efectos sobre el desarrollo de esta disciplina. Jodelet (1986) esclarece que las representaciones sociales son una modalidad de pensamiento práctico vinculada con el dominio y la comprensión del entorno social de quienes la construyen. De la misma manera, las representaciones sociales se han propagado a otras líneas de investigación. Al respecto, Jodelet (1986) añade que, "Representación social: un término que actualmente encontramos en todas las ciencias sociales [...] constituye la designación de fenómenos múltiples que se observan y estudian a variados niveles de complejidad, individuales, colectivos, psicológicos y sociales" (p.469). Banchs (2000) aclara que, Jodelet se instala en el análisis de las producciones simbólicas (prejuicios, creencias) y, por ello, pone las bases para comprender a las personas como productoras de sentido. 
Por lo antes expresado, las representaciones sociales se circunscriben a los márgenes que le destinan los teóricos. En el caso de Moscovici (1979), Jodelet (1986) y Herzlich (1975) se toma en consideración el contexto cultural y social; son más proclives a la perspectiva cualitativa del enfoque procesual. Admiten que las representaciones sociales se constituyen como elementos prácticos en los vínculos sociales de quienes las comparten. Poseen un carácter autónomo, creativo, simbólico y significante, atraviesan los ámbitos individuales, imaginarios y sociales. En palabras de Jodelet (1986): "las representaciones sociales se presentarán bajo formas más o menos complejas. Imágenes que condensan un conjunto de significados: sistemas de referencia que nos permiten interpretar lo que nos sucede" (p. 472).

Por otro lado, algunas investigaciones que ensalzan la perspectiva cuantitativa de las representaciones sociales son coincidentes con el enfoque estructural. En esta postura se sitúan Abric (2001), Flament (2001), Guimelli y Rouquette (1992).

Abric (2001), uno de los autores más fecundos, evidencia que a las dimensiones información, campo de representación y actitud, elucidadas por Moscovici, deben añadírseles una organización y un análisis (se refiere a la estructura interna o cognitiva de la representación); es decir, hay que priorizar la organización jerárquica del núcleo central y sus elementos periféricos. Para lograrlo, propone una pluralidad de técnicas de acopio de información tales como: cuestionarios estructurados, soportes gráficos, aproximaciones monográficas, carta asociativa y tablas inductoras (Abric, 2001).

\section{Procedimientos metodológicos}

Los marcos de referencia de las representaciones sociales tienen importantes implicaciones, por un lado, enfatizan la funcionalidad, y, por otro, sirven como herramientas que orientan el despliegue de las interacciones entre el estudiantado normalista (aprendices de maestro) y el alumnado adolescente de la escuela secundaria. Importa aclarar que se instaura la metodología cualitativa y, ante todo, se recuperan los postulados de la vertiente procesual (Moscovici, 1979; Jodelet, 1986; 1991). Se justifica, además, por la escasez de estudios sobre la línea de las y los adolescentes, en particular situándolos en las aulas de las escuelas secundarias. De ahí que remarcar las representaciones sociales establecidas en un contexto social e histórico, se traduce en un principio nodal y promisorio para la comprensión de la cultura y el contexto donde se producen; engloba en sí, un proceso tal y como se les presenta a las y los informantes.

Cabe mencionar que el trabajo de campo se llevó a cabo en los meses de febrero-abril de 2018. De una población de 35 alumnas y alumnos pertenecientes a la especialidad de español, se eligió de manera circunstancial una muestra de 15 aprendices: 13 mujeres y 2 hombres que estuvieran cursando el octavo semestre de la licenciatura en educación secundaria. El proceso adoptado se expresa a continuación.

Se puso a disposición de las y los estudiantes el proyecto de investigación. Se resaltaron los propósitos, la importancia que tenía su intervención y el uso confidencial de los datos recabados. Además, se incluyeron los ejes temáticos que servirían de guía para la conversación (formato de entrevista). Luego que aceptaron, se procedió a solicitarles las fechas exactas en que podrían conceder la entrevista. Se realizó una agenda y se procedió a su realización.

La mayoría tomó la decisión de llevar a cabo la entrevista en la biblioteca de la Escuela Normal, solo dos solicitaron que el sitio para la entrevista se concretara en su escuela secundaria de práctica en horarios específicos. La duración de cada entrevista fue de una hora y media, aproximadamente. Una vez finalizadas las grabaciones, se requirió que las y los informantes escucharán su respectivo testimonio, esto con la finalidad de detectar alguna información que se considerara inadecuada para la publicación de este estudio. Se procedió a la cancelación de algunos fragmentos de sus testimonios y, al final, dieron la anuencia para utilizar el resto.

En cuanto al criterio de selección, se les consideró informantes clave por ser quienes tienen más tiempo en la formación de enseñante de la escuela secundaria. Para el acopio de información, se ha descrito en párrafos atrás, se procedió a la elaboración de un guion de entrevista a profundidad, en razón de que 
constituye una técnica idónea para aprehender las percepciones, creencias, pensamientos y sentimientos. En concreto, se detallan dos ejes temáticos: el primero instaura la caracterización de las y los informantes (sexo, edad, actividades laborales que desempeñan). El segundo, aborda los conflictos más recurrentes, así como las actitudes, intereses, interacciones y acciones de las y los adolescentes con quienes interactúan. Para mantener la confiabilidad de los resultados, una vez finalizada la totalidad de las entrevistas, se procedió a su transcripción literal, para luego leer, releer, analizar e identificar la construcción de las categorías socialmente compartidas, dejando fuera cualquier referente empírico asociado con puntos de vista no coincidentes con las representaciones sociales del grupo de informantes.

\section{ANÁLISIS Y DISCUSIÓN DE RESULTADOS}

Se ha referido que al analizar los resultados de las entrevistas se pudo corroborar que los aprendices de maestro integraron sus representaciones sociales atendiendo a la diferenciación entre las y los adolescentes que cursaban un grado y otro; es decir, atribuyeron especificidades de sus representaciones sociales a las y los adolescentes de acuerdo a si cursaban el primero, segundo o tercer grado de la escuela secundaria.

Por lo tanto, en los apartados siguientes, se ilustra un orden que no sólo caracteriza a las y los informantes, sino también proporciona un esquema de representaciones sociales que difieren entre sí al dar indicios de una percepción sobre la manera peculiar en que se ha dicho, las y los aprendices de maestro expresan sobre el alumnado de la escuela secundaria. Variantes que, por consiguiente, se interpretan a la par del grado que $\operatorname{cursan}\left(1^{\circ}, 2^{\circ}\right.$ y $\left.3^{\circ}\right)$.

Cabe aclarar que involucrarse en la investigación de un escenario del cual la autora forma parte, puede constituir un obstáculo para la objetividad de este estudio, sin embargo, la vigilancia epistemológica expresada por Bourdieu (2008), incide en desapartarla de una visión sectaria.

\section{Caracterización de las y los informantes (aprendices de maestro)}

De acuerdo con los rasgos de edad, sexo, estado civil, y ocupación de las y los 15 aprendices de maestro, se esclarece que fueron 13 mujeres y 2 hombres. El estado civil fue de 4 casadas (sólo mujeres) y 11 solteros ( 9 mujeres y 2 hombres). Sobre la edad de las mujeres, 9 oscilan entre 22-25 años y 4 entre 26-28. En relación con los hombres, 2 tienen entre 23-25 años. Con respecto a sus actividades laborales, 13 trabajan (11 mujeres y 2 hombres). Sobre el trabajo que desempeñan las mujeres, 6 realizan actividades de comercio, 1 es mesera, 2 son estilistas, 2 realizan quehaceres domésticos. Con respecto a los 2 hombres, 1 se dedica al comercio informal y el otro es cajero de una tienda de autoservicio.

\section{Representaciones sociales sobre las y los adolescentes de primer grado: Regresión al ambiente escolar de nivel primaria}

Las representaciones sociales que expresan las y los aprendices de maestro sobre las y los adolescentes que cursan el primer grado de secundaria mantienen tendencias focalizadas hacia los rituales escolares con los que convivieron durante su permanencia en el nivel primaria. Para McLaren (2003), el ritual está repleto de símbolos, cosmovisiones y resistencias. Los rituales son fuentes simbólicas transmisoras de cultura y las instituciones educativas, así como muchas otras, las promueven mediante los procesos de socialización. En este caso, las y los aprendices mencionan que las y los alumnos de primer grado están condicionados con prácticas sedimentadas aprendidas en la escuela primaria.

Esa lógica de entendimiento de las y los adolescentes requiere que las y los maestros en formación adapten sus prácticas docentes a los requerimientos, expectativas y actitudes concernientes a una imagen asignada al 
profesorado de nivel primaria. A este respecto, se observa que las y los adolescentes de primer grado no han roto con la significación que tienen sobre el nivel educativo que les precede y, por ende, se orientan y actúan a través del acompañamiento casi permanente de las y los aprendices de maestro; baste recordar que debe orientárseles sobre el qué y el cómo de sus actividades en el aula, sin dejar fuera que las tareas extraescolares deben redactarse en el pizarrón y que el clima de distracciones y desinterés por tomar apuntes se vuelve cotidiano; en ese punto es notorio un esquema constitutivo de lo que generalmente se dinamiza en el espacio social de la escuela primaria.

Las entrevistas lo ilustran de la siguiente manera:

Parecen niños de primaria, me preguntan qué es eso, cómo tienen que hacerlo, [...] voy a colocar la tarea en el pizarrón porque necesitan apuntarlo en sus cuadernos. [...] muchos se distraen, no ponen interés, no apuntan lo que les explico (Aprendiz de maestra 8, comunicación personal, 7 de febrero, 2018)

Los de primer grado [...] apenas habían pasado 5 minutos de haber anotado la tarea y seguían preguntando lo que tenían que [...] entregarme mañana, [...] se comportan como niños y yo actúo como maestra de primaria [...] todavía quieren que una les preste mucha atención (Aprendiz de maestra 4, comunicación personal, 2 de marzo, 2018).)

Otro componente de sus representaciones sociales sobre las y los adolescentes de primer grado son las continuas manifestaciones de dependencia que algunos entablan con sus padres de familia que, a la usanza del nivel primaria, inciden en continuar participando en algunas tareas extraescolares de carácter práctico que las y los docentes dejan para ser desarrollados por el alumnado. Ante ello, las y los aprendices de maestro captan una disonancia entre el hacedor de las tareas y la intervención indescifrable de un estudiantado que no tiene idea de cómo la hizo ni de qué trata.

Así lo anuncian:

Si dejas tareas a los de primer grado, no las hacen y si lo logran, lo hacen sus papás, [...] traen la tarea y no saben explicarla cuando se les pregunta cómo lo hicieron (Aprendiz de maestra 6, comunicación personal, 9 de marzo de 2018).

Varios trabajos están tan bien hechos que dudo los hayan elaborado los alumnos [...] a ver: explícanos cómo lo hiciste y se queda mudo el muchacho (Aprendiz de maestra 8, comunicación personal, 7 de febrero, 2018).

Se revela que las y los adolescentes de primer grado aún conservan los ordenamientos de una memoria lúdica, de la cual se derivan algunos comportamientos con respecto a los asuntos escolares. Este acervo de prácticas se manifiesta, por ejemplo, por el uso de los juguetes que todavía llevan consigo a los salones de clase. Sin embargo, cabe señalar que poco a poco las y los adolescentes toman distancia de estas actitudes, no por convicción personal, sino para evitar los regaños de su profesorado y las burlas de algunos compañeros que cursan otros grados escolares.

Lo manifiestan así:

Juegan entre ellos como si fueran estudiantes de nivel primaria; [...] durante los primeros meses de haber iniciado las clases en secundaria algunos traen algunos juguetes. Pero, al cabo de unos días, pienso que se cohíben porque los compañeros de otros grados se burlan de ellos; los maestros los regañan, y nadie lo mira bien [...] y comienzan a dejar de llevarlos [...]. No estás en primaria, ahora debes comportarte más maduro porque ya están cursando la escuela secundaria (Aprendiz de maestra 5, comunicación personal, 6 de febrero, 2018).

A decir de Wagner, Hayes y Palacios (2011), la representación social incluye una amalgama de pensamientos y actuaciones visibilizados sobre un determinado objeto social. En el caso de esta investigación, las representaciones sociales sobre las y los alumnos de las escuelas secundarias de primer grado denotan acciones, dudas, apegos y condicionamientos que se han asentado no sólo en sus prácticas cotidianas, sino también en las y los aprendices de maestro, quienes captan e incorporan la imagen de un profesorado de nivel primaria como una base significativa para comunicarse con las y los adolescentes. 


\section{Representaciones sociales sobre las y los adolescentes de segundo grado: Un ambiente de incertidumbre}

Las representaciones sociales sobre las y los adolescentes que cursan el segundo grado de estudios conllevan formas de organización que no admiten los principios institucionales que los regulan. Éstas denotan una amplia gama de conductas donde prevalece la impuntualidad, el escándalo, el desgano por estudiar, la rebeldía, todo lo que en suma constituye una señal de resistencia que anuncia un mundo ordenado a modo e independiente del marco de referencia de las y los aprendices de maestro.

Terminó el recreo y los muchachos no querían pasar al salón de clases [...] pasaron 5 minutos y al fin entraron, y en lugar de sacar sus cuadernos comenzaron a gritar a todo pulmón sin importarles que yo estuviera ahí [...]. No hicieron nada, no me pusieron atención, eran rebeldes [...] tenían prisa por salirse del salón, por irse a divertir; sus intereses eran otros, su mundo también (Aprendiz de maestro 1, comunicación personal, 8 de febrero, 2018).

Los de segundo grado, ese día estaban más escandalosos que nunca, [...] entraron tarde a mi clase, seguían jugando y los gritos no cesaban, no ponían atención, simplemente no querían aprender nada, [...] convirtieron al salón de clases en un lugar aparte (Aprendiz de maestra 8, comunicación personal, 7 de febrero,2018).

Otra representación social muestra el desinterés sobre algunas prácticas del acontecer cotidiano en las aulas, como el pase de lista y la entrega de tareas. Esto condiciona una relación poco estable para la o el aprendiz de maestro que, en aras de solucionar esas inconsistencias, trata de ser coercitivo, pero no encuentra las respuestas esperadas entre ellos.

Estaba con los de segundo grado, inicié pase de lista, nadie contestaba, pregunté sobre la tarea y me ignoraron. Traté de llamar su atención con la exposición de mi clase y estaban ausentes, [...] comencé a desesperarme y exigirles más, comenté que daría por vista esa clase, pero no tuve éxito (Aprendiz de maestro 2, comunicación personal, 20 de abril, 2018).

Las y los aprendices de maestro señalan que en cierta medida las y los adolescentes de segundo grado se insertan en un clima de tensiones porque cursan un grado sándwich que no los coloca en riesgo. En primer lugar, porque ya superaron el noviciado de primer grado; en segundo lugar, porque ya se reconocen como parte importante de la escuela; en tercer lugar, porque no arriesgan nada; y, por último, existe una tradición que identifica al segundo grado como los más desmadrosos y temidos de la escuela; términos de referencia que, por añadidura, parecieran reconocer como conductas funcionales que les han sido socialmente heredadas. Cabe resaltar que lo referido, implica una transición entre un estudiantado que durante el primer grado hizo evidentes las diversas dificultades para integrarse a la nueva cultura escolar del nivel secundaria, y un estudiantado que actualmente cursa el segundo grado y que traspasa los límites de la disciplina, pero que además es consciente de sus procesos de cambio. Dicho de otra manera, durante el proceso de desplazamiento de un grado a otro, incorporan una realidad que los involucra con prácticas naturalizadas, vale decir, consideran como algo normal que cursar el segundo grado es sinónimo de desobediencia a los mandatos que les impone el orden institucional. De acuerdo con Brewer (2001) el sentido de pertenencia los obliga a participar de manera activa en la unificación del colectivo.

A decir de las y los aprendices de maestro:

Los alumnos de segundo grado ya superaron la etapa de primer grado [...] no sé, creo, porque están en el grado sándwich todavía no les afectan tanto las calificaciones, entonces son más confiados y más inquietos, es agotador trabajar con ellos [...] si les reclamo dicen: ¡ay maestro!, todos saben que los de segundo grado somos los más ‘desmadrosos' y 'temidos de la escuela' (Aprendiz de maestro 1, comunicación personal, 8 de febrero, 2018).

Los de segundo grado, los sandwiches [...] la reprobación no los coloca en riesgo [...] ya superaron el primer grado cuando eran novatos; conocen a detalle a la escuela, se integraron [...] se dan mucha importancia (Aprendiz de maestra 6, comunicación personal, 9 de marzo, 2018). 
En la misma sintonía, las y los adolescentes de segundo grado discurren entre actividades que dejan inconclusas, ruidos, gritos, que, en suma, no terminan jamás; éste es el escenario escolar donde las y los aprendices de maestro desarrollan su trabajo.

Lo refieren así:

Percibo poco interés en los temas que les imparto, [...] un alumno comienza a leer y les pido a los otros que le den secuencia a la lectura, y nadie ha puesto atención, ni siquiera saben en qué párrafo se quedó su compañero (Aprendiz de maestra 5, comunicación personal, 6 de febrero, 2018).

Los alumnos de segundo grado no me ponen atención, entonces, deambulo entre las filas, explico y los estudiantes continúan con sus risas y gritos, a veces logro que bajen la voz, una vez que les he llamado la atención, pero luego insisten, es el cuento de jamás terminar (Aprendiz de maestra 3, comunicación personal, 17 de abril, 2018).

Otras actitudes que componen el cuadro representacional de las y los adolescentes de segundo grado (ruidos, escándalos, desinterés por el estudio), tienen relación con la adopción de actitudes en las que predomina la falta de interés, por atender las recomendaciones que hacen las y los aprendices de maestro sobre las tareas a realizar en casa. En este punto, por ejemplo, les resulta efectivo gritar para que la voz de la o el maestro no se escuche y, así, poner como pretexto que no hicieron las actividades porque no lograron distinguir la forma en que debían organizar sus trabajos. Así lo describen:

Finaliza la sesión de clases, y los alumnos que cursan el segundo grado insisten en hablar y hacer ruido, mi voz se apagaba entre tanto bullicio, mis recomendaciones no eran escuchadas por todos, quiero pensar que posiblemente lo hacían a propósito para que mañana tuvieran el pretexto de que no escucharon nada y no sabían que tenían tarea (Aprendiz de maestro 2, comunicación personal, 20 de abril, 2018).

Como puede constatarse, el aspecto más sobresaliente de las representaciones sociales sobre las y los adolescentes de segundo grado define un vínculo inestable entre ambas partes. Se configuran nociones que modelan tendencias hacia la dispersión, los escándalos, la impuntualidad, el desgano por estudiar, la evasión de responsabilidades, la desatención a las indicaciones para la realización de tareas. Directrices que, en suma, desencadenan en el escenario de actuación un clima de tensiones que agota a las y los aprendices de maestro, y al mismo tiempo se convierte en un obstáculo para que las y los adolescentes comprendan las temáticas tratadas en clases. Así, en función de las concepciones que se tienen sobre las y los adolescentes de segundo grado, prevalece un orden poco amistoso que no contribuye a estructurar un clima de interacción grato.

Se ha mencionado que existen representaciones sociales asociadas a la idea de un sándwich; implica resguardarse en un sitio seguro, sin afectaciones escolares.

Por otro lado, las y los adolescentes asumen posturas que privilegian el manejo de un tiempo que va más allá de lo que pueden experimentar cotidianamente las y los aprendices de maestro, Hargreaves (1999) considera que el tiempo pone énfasis en una restricción que resulta opresora e incluso refleja configuraciones del poder. En este sentido, resulta posible interpretar que las y los adolescentes de segundo grado intentan quebrantar las reglas a través de anular la intervención de las y los aprendices de maestro.

\section{Representaciones sociales de las y los adolescentes de tercer grado}

Las representaciones sociales sobre las y los adolescentes del tercer grado no se comparan con quienes cursan los grados que les preceden. El cambio se describe a través de la creación de ambientes de aprendizaje donde imperan intercambios poco discrepantes. Sus interacciones se desarrollan adoptando las regulaciones institucionales, pero especialmente, las que establecen las o los aprendices de maestro. Se describe a continuación. 


\section{Las y los alumnos de tercer grado son bien portados}

Las representaciones sociales sobre las y los adolescentes de tercer grado señalan la buena disposición que tienen para acatar la disciplina escolar. Esas dinámicas de interacción en las cuales privilegian la docilidad para encarar sus actividades escolares obedecen a su interés por obtener el certificado de estudios e incursionar sin problemas en el nivel bachillerato.

En sus palabras:

La mayoría de los muchachos de tercer grado son más dóciles, y pareciera que quieren aprender, pero no me sorprendería que lo hagan porque no quieren tener conflictos con sus calificaciones y así obtener su certificado limpio para poder acceder al nivel bachillerato sin ningún contratiempo (Aprendiz de maestro 1, comunicación personal, 8 de febrero, 2018).

Tratan en lo posible de conservar la calma para que no se atoren y puedan concluir su secundaria sin adeudar materias de la escuela secundaria [...] y no represente problema para llegar al bachillerato (Aprendiz de maestro 2, comunicación personal, 20 de abril, 2018).

Las representaciones sociales sobre las y los adolescentes de tercer grado tratan de satisfacer las expectativas de las y los maestros. Expresan actitudes que tienen como denominador común el mantenimiento de principios de puntualidad en la entrega de sus tareas, disponibilidad para el estudio, y en términos generales, insisten en poner en juego las destrezas requeridas para llevar a buen fin su salida de la escuela secundaria.

Así lo expresan:

Los chicos de tercero tratan en lo posible de seguir mis recomendaciones académicas. [...] algunos se esmeran por hacer un buen papel, se aplican invirtiéndole tiempo al estudio, saben que está en juego su salida de la escuela (Aprendiz de maestra 9, comunicación personal, 12 de abril, 2018).

$\mathrm{Al}$ mismo tiempo, señalan la importancia de verse bien y, por ello, ensalzan su apariencia personal como una de sus prioridades. Otro signo que les caracteriza es entablar cercanía con la novia o el novio. Estas manifestaciones amorosas son propias de este grado, pero resultan desaprobatorias para las y los adolescentes que cursan primero y segundo grado de la escuela secundaria.

Si revisas el uniforme y presentación de los muchachos de la secundaria notarán que los de tercer grado son más cuidadosos, $[\ldots]$ andan de novieros y no les importa que todos los vean. Las autoridades no les dicen nada, simplemente porque van en tercero (Aprendiz de maestra 4, comunicación personal, 2 de marzo, 2018).

Los adolescentes de tercer grado ya muestran abiertamente sus vínculos amorosos con sus parejas. [...] Se abrazan, besan, toman de la mano a su pareja [...] eso no es permitido en los adolescentes que cursan grados anteriores (Aprendiz de maestra10, comunicación personal, 16 de abril, 2018).

En el mismo sentido, las y los alumnos de tercero se encuentran en un ciclo escolar que está por concluir y, sabedores de ello, valoran el intercambio afectivo. Así, esta tendencia clarifica diálogos más acordes a su futuro como estudiantes y manifiestan el interés por continuar vínculos de amistad con sus actuales compañeros.

Así lo exponen:

Al faltar pocos meses para salir de la secundaria, los muchachos muestran más afectos entre ellos, platican sobre las escuelas que eligieron para estudiar el bachillerato y algunos hablan sobre la posibilidad de seguirse viendo (Aprendiz de maestro 1, comunicación personal, 8 de febrero, 2018).

Cursar el último grado los posiciona en un nivel de jerarquía muy por encima de sus compañeros de segundo y primero. De este modo, tratan de poner en evidencia que sus relaciones de noviazgo, sean o no concordantes con la disciplina escolar, las ejercerán sin esconderse de la mirada de los otros; lo que es un privilegio obtenido por el estatus de pertenecer al último ciclo de su formación en la escuela secundaria.

Recapitulando, por las imágenes que las y los aprendices de maestro conforman sobre el alumnado de los tres grados de la escuela secundaria pueden precisarse algunas características comunes según el grado cursado. Las y los adolescentes de primer grado demandan mayor atención ante las dificultades que tienen 
para integrarse a una estructura organizativa, en la que las materias son impartidas por diferentes maestras y maestros, a diferencia de la primaria, en la que sólo tenían una maestra o maestro que se encargaba de dirigir las clases.

Por su parte, las y los adolescentes de segundo grado son representados con incertidumbres y, por ello, cobran un orden distinto en sus interacciones. Reconocen que pesa sobre ellos el estigma: desmadrosos $y$ temidos de la escuela, y lo hacen valer al orientarlas en la lógica que más les convenga. Sabedores de que el grado que cursan no les sitúa en peligro justifican cualquier procedimiento, incluido el desorden y el descuido escolar. A este respecto, las y los aprendices de maestro prefieren evitar la confrontación al reconocer las consecuencias que puede acarrearles, dada su condición de aprendices.

Por otro lado, las representaciones sociales adjudicadas a las y los adolescentes de tercer grado denotan actitudes validadas por las instituciones educativas al ceñirse de los indicadores que se les exigen como una forma de mantener un buen equilibrio en su desempeño escolar. En ese sentido, las y los estudiantes de tercero han dejado atrás las actitudes infantiles, el desinterés y desorden para afrontar con mayor celeridad sus actividades escolares. No cuestionan las acciones ni prácticas que desarrollan los miembros de la comunidad escolar y prefieren participar de manera responsable en función de lo motivante que resulta la opción de continuar con el siguiente peldaño escolar, la escuela de nivel medio superior o bachillerato.

Las representaciones sociales que construyeron las y los aprendices de maestro sobre las y los adolescentes de la escuela secundaria refieren las afinidades que se dieron entre los pares en sus respectivos recintos escolares. Esas representaciones ofrecieron imágenes que les permitieron tener una forma distinta de interacción con ellos. Sin embargo, el carácter dinámico de las representaciones sociales también dejó entrever que una vez que las y los adolescentes de un determinado grado arriban al siguiente, abandonan el molde representacional que les ha sido asignado e, inmediatamente, asumen el mismo encuadre de manifestaciones de aquellos que les dejaron su lugar.

\section{Conclusiones}

Las experiencias vertidas muestran a las y los aprendices de maestro inmersos en la vida cotidiana de las aulas de las escuelas secundarias, interactuando con diversos conflictos y atendiendo a las exigencias de los grupos de adolescentes que les han asignado.

Desde el marco general de las representaciones sociales de las y los aprendices de maestro con respecto a las y los adolescentes de primer grado, puede vislumbrarse un tejido de significados discrepantes entre las formas diseñadas para organizar los espacios, tiempos, contenidos curriculares y situaciones didácticas que ofrece la escuela primaria y el escenario de una escuela secundaria presidida por normas más rígidas, saberes más diversificados y un equipo docente que les imponen su personalidad, su lógica de entendimiento, su marco cultural. ¿Cómo adaptar a las y los adolescentes a la complejidad del contexto de la escuela secundaria, si unos meses atrás todavía eran tratados como niños? Al respecto, conviene recordar, que, las y los aprendices de maestro consideran que la escuela secundaria permanece al margen de las experiencias escolares de las y los estudiantes de primer grado, por ello, existe un clima de desapego por todo aquello que el profesorado de este nivel pone a su alcance. Sin embargo, las y los aprendices de maestro consideran que proveerlos de lenguajes de apoyo y acompañamiento, tal como lo hacía el profesorado que le precedió puede ser una de las soluciones mientras se acomodan a su nueva realidad educativa.

Una tendencia contraria, aparece en las y los adolescentes de segundo grado. Ellas y ellos se han integrado a la escuela de manera óptima, tanto que promueven la incorporación de la marca que los cohesiona e identifica como los temidos y desmadrosos de la escuela. En ese sentido, asumen una etiqueta que suele pertenecerles a quienes ocupan el segundo grado de la escuela secundaria. Por último, las y los adolescentes del tercer grado, que casi tienen un pie fuera de la escuela, se focalizan en mantener un estatus que los identifica con las formas flexibles que utilizan las autoridades de la escuela para aplicarles las reglas. 
Por lo dicho, puede considerase que las y los adolescentes de primer grado apenas reconocen el territorio e intentan integrarse; los de segundo grado no sólo se integraron, sino que abusan de su posición, casi invulnerable por el estado que guarda un grado que no los compromete de ninguna manera con sus obligaciones escolares; y, por último, las y los adolescentes de tercer grado se tornan tranquilos y comprometidos, porque intentan salvaguardar su estancia para obtener un certificado de estudios que les permita ingresar al siguiente nivel educativo.

Por su parte, las y los aprendices de maestro supeditaron su práctica docente a las premisas de sus representaciones. Con las y los adolescentes de primer grado asumieron una postura relajada y a veces hasta maternal; con el estudiantado de segundo grado mantuvieron una tensión constante que los obligaba a permanecer como hablantes a los cuales nadie quiere escuchar. Para finalizar, las y los adolescentes de tercer grado asumieron actitudes que favorecieron un ambiente fértil para que las y los aprendices de maestro participaran de manera más activa frente a grupo.

$\mathrm{Al}$ analizar las acciones de las y los aprendices de maestro, el presente estudio deja consideraciones pendientes. Por ello, es necesario decir que las representaciones de las y los adolescentes, vistas desde las prácticas docentes de las y los maestros en formación, tendrían que triangularse por medio del uso de otros instrumentos de acopio de información a través de los cuales la o el docente titular de la asignatura exprese la otra subjetividad que no fue objetivada. En otras palabras, recuperar la forma en que participaron cuando las y los aprendices de maestro no pudieron controlar las tensiones que fluían dentro de los grupos de los distintos grados, especialmente en los de segundo grado. De esa manera se conjugarían más puntos de vista y la producción de conocimiento sobre las referidas representaciones sociales resultarían más enriquecedoras. Es importante mencionar que la teoría de las representaciones sociales ejerce gran influencia en el campo de la adolescencia, pues abona a que circulen lenguajes que rompen las fronteras entre las perspectivas conservadoras, que enuncian a manera de un manual lo que debe ser un adolescente, y la forma en la que es concebida por aquellos que reconocen sus marcos de intervención y la forma en que crean y recrean algunos fenómenos de su realidad social.

Finalmente, cabe aclarar que las y los adolescentes ubicados en cada grado escolar compartieron un ambiente funcional que ha sido determinado por sus propias dinámicas de interacción; sin embargo, no necesariamente simbolizan a la totalidad de las y los adolescentes de las escuelas secundarias de la Ciudad de México.

\section{REFERENCIAS BIBLIOGRÁFICAS}

Abric, J. (2001). Prácticas sociales y representaciones. México: Ediciones Coyoacán.

Araya, S. (2002). Las representaciones sociales. Ejes teóricos para su discusión. Costa Rica: Facultad Latinoamericana de Ciencias Sociales (FLACSO).

Banchs, M (2000). Aproximaciones procesuales y estructurales al estudio de las representaciones sociales. Papers on Social Representations, 9, 1-15. Recuperado de http://www.psr.jku.at/PSR2000/9_3Banch.pdF

Bourdieu, P. (2008). El oficio del sociólogo. México: Siglo XXI.

Brewer, M. (2001). The many faces of social identity: Implications for political Psychology. Political Psichology, 22(1), 115-125.

Carr, W. (1998). Calidad de la enseñanza e investigación-acción. Sevilla: Diada. Sevilla: Diada.

Carr, W. (2002). Una teoría para la educación: Hacia una investigación educativa crítica. Madrid: Morata.

Contreras, D.J. (1990). Enseñanza, currículum y profesorado. Introducción crítica de la didáctica. Madrid: Akal.

De Lella, C. (1999). Modelos y tendencias de la formación docente. En Desarrollo escolar. Seminario llevado a cabo en la Organización de Estados Iberoamericanos, Perú. Recuperado de https://www.oei.es/historico/cayetano.htm

Erickson, E.H. (2004). Sociedad y adolescencia. México: Siglo XXI editores. 
Feixas, M. (2010). Enfoques y concepciones docentes en la Universidad. Revista Relieve 16(2), 1-27. Recuperado de h ttps://www.uv.es/RELIEVE/v16n2/RELIEVEv16n2_2.pdf

Fize, M. (2004). ¿Adolescentes en crisis?: Por el derecho al reconocimiento social. México: Siglo XXI editores.

Flament, C. (2001). Estructura, Dinámica y Transformación de las Representaciones sociales. En. J. Abric (Dir.), Prácticas sociales y representaciones (pp. 33-52). Distrito Federal, México: Ediciones Coyoacán.

Guimelli, C., y Rouquette, M. (1992). Contribution du modéle associati des schémes cognitifs de base á l'analyse structurale des représentations sociales. Bulletin de Psichologie, 45(405), 196-202.

Gutiérrez, E. (2011). Del mesabanco a la tarima del maestro: los significados de los estudiantes normalistas. En I. Lozano y E. Mercado (coord.). El ojo del huracán. La formación y la práctica del docente de secundaria. Miradas divergentes (pp.55-73). Ciudad de México, México: Díaz de Santos.

Gutiérrez, E. (2013). Representaciones sociales de la práctica escolar de los estudiantes de la Escuela Normal Superior de México. En H. Aguayo. (Coord.) Investigación en la escuela: El sentido de los datos desde la tradición compresiva (pp. 171-192). México: Díaz de Santos.

Gutiérrez, E. (2018). La primera práctica docente durante la formación inicial. En E. Gutiérrez. (coord.). Prácticas, saberes y experiencias: Voces de estudiantes y docentes (pp.43-71). México: Newton.

Hargreaves, A. (1999). Profesorado, cultura y postmodernidad. (Cambian los tiempos, cambia el profesorado). Madrid, España: Morata.

Hernández, G. (2011). Práctica docente. Más allá de cuatro paredes, pizarrón y mesabancos. México: Arana Editores.

Herzlich, C. (1975). La representación social. En Sergei Moscovici (Ed.). Introducción a la psicología social. Barcelona: Planeta.

Jodelet, D. (1986). La representación social: fenómenos, conceptos y teoría. En S. Moscovici. (Comp.), Psicología social II. Barcelona, España: Paidós.

Jodelet, D. (1991). Representaciones sociales: un área de expansión En D. Páez y otros (Comp.). Sida: Imagen y prevención (pp.25-56) Madrid: Fundamentos.

Jodelet, D. (2011). Aportes del enfoque de las representaciones sociales al campo de la educación. Espacio en Blanco. Revista de Educación, (21). 133-154. Recuperado de https://www.redalyc.org/pdf/3845/384539803006.pdf

Krauskopf, D. (2000). Dimensiones críticas en la participación social de las juventudes. En S.Balardini (Comp.).La participación social y politica de los jóvenes en el horizonte del nuevo siglo.(pp.119-134). Buenos Aires: Consejo Latinoamericano de Ciencias Sociales.

Levinson, B. (2012). Reduciendo brechas entre cultura juvenil y cultura escolar docente en América Latina: el desafío institucional para crear una secundaria con sentido. En E.Tenti (Coord.), La escolarización de los adolescentes: desafios culturales pedagógicos y de politica educativa. (pp.79-112). Buenos Aires: UNESCO.

Lozano, I. (2010). Sobre (vivir) la escuela secundaria. La voz de los alumnos. México: Díaz de Santos.

Martínez, F. (2012). Procedimientos para el estudio de las prácticas docentes. Revisión de la literatura. Relieve, 18(1), 495-544 Recuperado de https://ojs.uv.es/index.php/RELIEVE/article/view/2976/2546

McLaren, P. (2003). La escuela como un performance ritual. Hacia una economía política de los símbolos y gestos educativos. Distrito Federal, México: Siglo XXI editores.

Moscovici, S. (1979). El psicoanálisis, su imagen y su público. Argentina: Huemal.

Papalia, D.E., y Wendkos, S. (2001). Psicología. México: McGraw-Hill.

Sánchez, R. (1993). Didáctica de la problematización en el campo científico de la educación. Perfiles educativos, (61) 1-25. Recuperado de https://www.redalyc.org/pdf/132/13206108.pdf

Secretaría de Educación Pública (SEP). (2010). Plan de Estudios 1999 de la Licenciatura en Educación Secundaria. Documentos básicos. México: Programa para la Transformación y Fortalecimiento Académico de la Escuelas Normales.

Urbina, E. y Ovalles, A. (2018). Teoría de las representaciones sociales. Una aproximación al estado del arte en América Latina. Psicogente, 21(40), 495-544. 
Edith GutiérRez Álvarez. Representaciones sociales sobre las y los ADOLESCEnTEs: voces deL ESTUdia...

Wagner, W., Hayes, N. y Palacios, F (Eds.). (2011). El discurso de lo cotidiano y el sentido común. La teoria de las representaciones sociales. México: Anthropos.

\section{BY-NC-ND}

